\title{
Expectation from Technology and Career Satisfaction: A study among IT Professionals in India
}

\section{Gunjan Tomer}

Indian Institute of Management

Nagpur

f10gunjant@iimidr.ac.in

\section{Sushanta Mishra}

Indian Institute of Management

Indore

\section{Abstract}

Technology is an integral part of the work life of any information technology (IT) professional. However, the influence of technology on career related outcomes of IT professionals is at best limited. Using the P-E fit perspective, the present study investigated the implications of the perceived fit/ misfit between the expected and the experienced career growth and work-life balance from the technology the IT professionals are working in on their career satisfaction. Based on response surface methodology and polynomial regression analysis of the data collected from 286 IT professionals, the study found that not only the fit, but also the misfit between expected and experienced technology led career growth and work-life balance is important in explaining career satisfaction. Implications of the study for both research and practice were discussed.

Keywords: IT professionals, technology, P-E fit, career satisfaction, work-life balance.

\section{Introduction}

IT professionals play a critical role in sustaining competitive advantage of an organization (Ahmed, Taskin, Pauleen, \& Parker, 2017; Armstrong, Brooks, \& Riemenschneider, 2015). Hence, retaining the professionals and ensuring their high motivation level are important for organizations (Ahmed et al., 2017). To ensure their retention and productivity, it is essential that IT professionals hold positive valence to their work and career (Sarker, Sarker, \& Jana, 2010). In the present study we focused on career satisfaction among IT professionals for two reasons. One, it represents "an overall summary of how a person feels about a lifetime of work" (Lounsbury et al., 2007, p. 174) and signifies individual's perceived level of satisfaction in achieving desired career outcomes (Jiang \& Klein, 1999). Moreover, studies in different context have found that career satisfaction is related to individual outcomes such as positive valence (Fu \& Chen, 2015), life satisfaction (Lounsbury et al., 2004) and self-efficacy (Ngo \& Hui, 2018). Two, career satisfaction is related to work outcomes such as employee commitment, work engagement (Ngo \& Hui, 2018), citizenship performance (Jawahar \& Liu, 2016) and turnover intention (Rambur et al., 2005). Given the importance of career satisfaction, studies investigating the predictors of career satisfaction is at best limited ( $\mathrm{Ng}$, Eby, Sorensen, \& Feldman, 2005). In fact, scholars have argued that "challenge to increase employees' career satisfaction" is difficult (Han, 2010, p. 437), especially among IT professionals. Since technology ${ }^{1}$ is core to the functioning of IT professionals, in the present study, we proposed

\footnotetext{
${ }^{1}$ Given technology refers to the technology in which an IT professional is trained and working with.
} 
that perceived career related features of a technology might impact career satisfaction of these professionals.

Scholars have argued that individuals in the IT workforce are heterogeneous (Joseph et al., 2012), i.e., individuals evaluate a given technology differently based on their own perceptions and expectations (Speier \& Venkatesh, 2002). In fact, career outcomes of an individual working in a given technology depend on his/her own preferences and the ability of the technology to fulfil his/her career and work-related expectations. Since interaction with a given technology defines individual's work and career outcomes, in case of IT professionals, the unmet expectations can arise due to mismatch of expectations in a given technology. Scholars have found that unmet expectations from the job setting lead to negative work outcomes among IT professionals (Chilton, Hardgrave, \& Armstrong, 2005; Igbaria, Greenhaus, \& Parasuraman, 1991; Lee, 2011). Unfortunately, studies providing explanations regarding how an IT professional evaluates a given technology are limited.

Technology is not a homogeneous factor. Some technologies are widely accepted in the industry compared to other technologies. As a result, working in some technologies increase market value of the professionals compared to working in other technologies. Although demand of IT professionals is growing with time, professionals working in certain technologies may receive better job offers than their counterparts (Moreno et al., 2012). This leads to increased preferences for acquiring skillsets in some technologies compared to other technologies. It creates differential expectations for high demand technologies among the ambitious professionals. However, the expectations from a technology depend on both the individual and technological prospects. For instance, one professional might prefer to maintain work-life balance instead of working in a demanding technology. On the other hand, another professional may prefer working in a demanding technology over work-life balance. Thus, the fit/ misfit between the professional's expectation and the technology he/she is currently working in might explain his/her career satisfaction. Despite a reasonable literature on career satisfaction, challenges persist, indicating, the need for further research especially among the IT professionals. In the present study, we have investigated career satisfaction through the lens of person-environment (P-E) fit. Our argument is based on the assumption that the fit/misfit between the expectation and experience of working in a technology will explain career satisfaction among the IT professionals.

\section{Literature Review}

While all the diverse activities and experiences comprise one's career (Lounsbury et al., 2007), the extent to which an IT professional expresses a positive orientation towards his or her career is termed as career satisfaction (Fu \& Chen, 2015). Career satisfaction depends on how well individual career desires are getting fulfilled by the current job (Jiang \& Klein, 1999). Scholars suggest that fulfillment of career growth expectation leads to many positive organizational outcomes (Gupta, Guimaraes, \& Raghunathan, 1992). Given the importance of career for the IT professionals, there is a pressing need for the organizations to explore ways to manage career expectations of these professionals (Igbaria et al., 1991). In the present study, we investigated career satisfaction of IT professionals by exploring the dynamics related to technology. Technology is argued to be at the core of the functioning of these professionals and it defines their work fulfillment, job satisfaction and career growth (Hsu et al., 2003; Speier \& Venkatesh, 2002). Surprisingly, studies exploring the role of 'technology' on career prospects of IT professionals are limited. 
In the present study, we borrowed from the Person-environment (P-E) fit theory (Edwards et al., 2006, Kristof-Brown et al., 2005) to explain the linkages between the aspects of technology and career satisfaction of IT professionals. The fit approach is well accepted in the information systems (IS) literature to understand individual's perception about the job and the work settings (Ayyagari et al., 2011; Igbaria et al., 1991; Venkatesh et al., 2017). The basic premise of the P-E fit theory is that perceptions, attitudes, and behaviours of individuals are not determined only by the person level factors or the environmental factors independently but from the interactions between them. The 'environmental' factors have been redefined in various theories to explain the congruence of individuals with different aspects of their environment such as Person-Job fit and Person-Organization fit. We focused on technology aspect of the 'environment' in explaining the work outcomes of IT professionals.

\subsection{Technology led Career Growth (TCG)}

Drawing from the P-E fit theory, the need-supply framework explains individual behaviour. It captures two important dimensions, first, the needs of an individual and second, how the needs of an individual are fulfilled by the environment. The conceptualization of need-supply fit implies that when an individual's job fits his/her career needs, it will lead to increased career satisfaction (Kristof-Brown et al., 2005; Rehfuss, Gambrell, \& Meyer, 2012). Thus, the fit between IT professional's expectation from the work and the work positions he/she currently holds is positively related to career satisfaction (Igbaria et al., 1991). Based on the importance of congruence, several studies in IS literature has employed the P-E fit theory to explain career satisfaction (Jiang et al., 2012; Venkatesh et al., 2017). Career growth captures an individual's perceptions of the development and advancement possibilities within an organization (Jans, 1989; Weng et al., 2010). Career growth thus consists of two aspects: One employee's efforts in developing his/ her professional abilities and meeting his/ her own career goals; two, receiving rewards and promotions from the organization commensurate to his/her abilities and contributions (Weng \& Hu, 2009). Scholars have argued that individuals' progress in attaining their career goals influence their outcomes such as career satisfaction (Weng et al., 2010). Technology being central to the working of IT professionals, it can offer better work opportunities and better chances of role progression. For example, aspects of technology, specifically job market demands are argued to influence the career consequences of an IT professional (Moreno et al., 2012). Since technology is accepted as central to the career growth of IT professionals, we argue that experienced growth in career due to working in a technology will positively impact their career satisfaction.

Hypothesis 1: The fit between the expected and the experienced career growth while working in a technology is positively related to career satisfaction.

\subsection{Technology led Work-Life Balance (TWLB)}

The degree "to which an individual is simultaneously able to balance the temporal, emotional, and behavioural demands of both paid work and family responsibilities" is termed as worklife balance (Hill et al., 2001, p. 49). Literature has suggested that decreased work-life balance (WLB) among the IT professionals may induce negative outcomes such as higher levels of stress and turnover intention (Moore, 2000). IT professionals experience both 'time based' and 'strain based' conflict. Coordination activities with the global work teams contribute to creating time-based conflict as IT professionals have to work according to different time zones (Sarker et al., 2010). On the other hand, highly technical and sometimes routine work contributes to strain-based conflict among IT professionals. For example, a certain set of 
technologies require the IT professionals to stay available professionally even beyond office hours. The technologies involved with maintenance, troubleshooting and debugging can be categorized in this group. IT professionals working in these technologies tend to experience conflicts in balancing their personal and professional lives. The perceived conflict between an individual's personal and work life while working in a given technology is expected to influence the perceived work-life balance (Chen, Powell, \& Greenhaus, 2009). With increasing demand in the workplace, scholars have noticed decreasing levels of WLB among the IT professionals (Tarafdar et al., 2007).

As individuals differ in their needs and preferences, their career expectations differ significantly. In fact, Ginzberg and Baroudi (1988) found varying degrees of career desires among IT professionals. They further noticed that a set of individuals give priority to personal lives over their professional lives. These individuals assign more emphasis on maintaining work-life balance (Sarker et al., 2010). Studies suggest that technology that one is working in influences his/her work life balance by influencing work load, work hours (Greenblatt, 2002) and work timings (Sarker et al., 2010). The discrepancy between the expected and experienced work-life balance might reduce career satisfaction (Hsu et al., 2003; Igbaria et al., 1991). We propose that if the expected work-life balance level is not achieved while working in a given technology, the individual will experience negative work outcomes such as decreased career satisfaction. On the other hand, if the individual achieves expected work-life balance while working in a given technology, it will enhance his/her career satisfaction.

Hypothesis 2: The fit between the expected and the experienced work-life balance while working in a technology is positively related to career satisfaction.

\subsection{Incongruence between Person and Technology}

In contrast to the concept of fit, misfit explains the mismatch between the expected and experienced work outcomes from the technology an IT professional is currently working in. While fit has been associated with significant work outcomes, a good number of studies investigated outcomes associated with misfit or incongruence (Chen et al., 2009; Furnham \& Schaeffer, 2011). The evidence from the literature suggest that incongruence between a person and his/her environment such as 'technology' leads to strong perceptions of work outcomes as compared to convergence or perceived fit. In the present study, we have explained whether misfit between the expected and experienced technology impacts IT professionals' career satisfaction. To argue this, we borrowed from the expectation theory (Porter \& Steers, 1973). Theoretically, expectations are argued to be impactful as they create anticipation about the situation in the mind of an individual and create a cognitive schema about what should occur (Locke, 1976). Thus, according to the expectation hypothesis, unmet expectation leads to increase in negative outcomes (Shockley \& Allen, 2018). In addition, the conceptualization of need-supply fit implies that an individual will experience higher positive mental state and lesser psychological stress when congruence occurs, i.e., his/her needs are met by the supply from the environment (Shockley \& Allen, 2018). Based on the above discussion, we propose that career dissatisfaction will be more when there is incongruence, i.e., the expectations for career growth or work-life balance is more, compared to the perceived career growth and work-life balance while working in a technology.

Hypothesis 3(a): Misfit between the expected and the experienced technology led career growth, such that the higher the expected career growth compared to the experienced career growth from working in the technology, there is a decrease in career satisfaction. 
Hypothesis 3(b): Misfit between expected and the experienced technology led work-life balance, such that the higher the expected work-life balance compared to the experienced work-life balance from working in the technology, there is a decrease in career satisfaction.

\section{Method}

\subsection{Operationalization of Constructs}

The operationalization of constructs was one of the methodological challenges in our study. In the P-E fit literature, the operationalization of constructs has been debated in multiple studies. The challenge lies in measuring the extent of fit between the person and the dimensions of the environment. While conceptualizing a fit model, it is imperative to understand the distinction between various models of fit under the overarching P-E fit theory. The first distinction is defined in terms of whether it is a need-supply fit (congruence between the need of an individual and what the environment is supplying) or abilities-demand fit (congruence between the abilities of an individual to meet the demand placed by the environment). Another distinction is between commensurate and non-commensurate measures. In the commensurate measure, the discrepancy between the reported P (person) and E (environment) are calculated. The commensurate measures ensure that the measurement of fit is approached on the same dimension. On the other hand, the noncommensurate dimension approach allows the researcher to use different dimensions to measure both the $\mathrm{P}$ and the $\mathrm{E}$ and then reconcile the two measures to capture the fit by some appropriate methods. Finding appropriate construct to operationalize both $\mathrm{P}$ and $\mathrm{E}$ dimension is another methodological challenge in the measurement of P-E fit.

In their excellent work on P-E fit, Edwards et al. (2006) favoured the use of commensurate measures to address research questions grounded in the P-E fit model. We thus used the commensurate measures: The person dimension captured the preferences for the outcomes of an IT professional while working in a technology and the environmental dimension captured the technology led outcomes supplied by the technology in which the concerned IT professional is currently working in.

\subsubsection{Atomistic approach versus molecular approach}

There are three basic approaches which are widely used in linking person and environment relationship. The atomistic approach allows the researchers to capture the person and environment component separately and then deduce the combination scores using statistical techniques. The molecular approach is followed when the assessment of fit is direct in a way where "how less" or "how more" (with respect to individuals' expectations) is captured directly from the respondents. In the molar approach the respondents are asked to assess the fit while responding and subsequently rate the extent of the perceived fit/match.

While evaluating and comparing these approaches, Edward and colleagues (2006) have suggested adopting these approaches in accordance with the research problem. In the present study, we have adopted the atomistic approach because it allows studying and observing the relative conceptual relevance of person and environment component measures. The atomistic approach also allows the use of commensurate measures which are believed to be more efficient in the context of P-E fit studies (Brown et al., 2012; Chen et al., 2009). Research design based on the atomistic approach records two component measures for each predictor variable on a commensurate scale. This presents another challenge of measuring and combining the component measure. 


\subsubsection{Difference score approach}

In organizational research, the difference score approach has been widely used in studies of congruence and fit. This approach offers a simplistic approach to obtain difference scores of two component measures. This difference, however, can be an algebraic difference, absolute value of algebraic difference or squared difference based on the proposed relationship (Dawis \& Lofquist, 1984). However, the extant literature establishes various methodological concerns (Edwards, 1994; Edwards \& Parry, 1993; Klein et al., 2009; Venkatesh \& Goyal, 2010) regarding usage of difference scoring while combining the component measures. Difference score approach is also criticized for its assumption of a linear relationship, as linear models do not adequately represent the relationship between two component measures (Edwards et al., 2006).

\subsubsection{Polynomial regression analysis}

Literature suggests that if non-linearity is expected, component measures should be analysed using polynomial regression analysis (PRA), which allows interaction of higher order terms in the measurement model (Atapattu et al., 2014; Edwards et al., 2006). In PRA, congruence is not conceptualized as a single score such as difference score, but it rather emphasizes the correspondence between the component measures. Congruence or fit is analysed as a continuous curve, not a point, thus, allowing a better understanding of the complex relationship dynamics of fit. Despite the advancement in analytical power, coefficients of PRA are complex to understand and interpret. To analyse the coefficients more clearly and to extract additional information Response surface methodology (RSM) is employed along with PRA. Response surface analysis involves studying the resulting surfaces which correspond to the polynomial regression equations. Thus, it provides both statistical and visual testing of the data.

\section{Research Design}

The present study attempts to explain the impact of the fit and misfit between the expectations and the experiences (career growth and work-life balance) while working in a given technology on career satisfaction of IT professionals.

\subsection{Sample Design}

The sample frame included IT professionals working in service-based IT organizations in India. We received 286 usable questionnaires for the study. About 58 percent of the respondents were in the age group of 24 to 28 years, 35 percent in the age group of 28 to 32 years and rest were beyond 32 years. The mean experience of the respondents was 42 months and median experience was 36 months. About 73 percent of the respondents were male, about 66 percent of the respondents were single, 24 percent were married, and 10 percent were married with children.

\subsection{Control Variables}

The most crucial challenge faced by researchers in establishing the robustness of their findings is the elimination of alternate explanations. Based on prior research, we controlled for age, gender, marital status (Greenhaus et al., 1990; Igbaria et al., 1991; Sarker et al., 2010; Weng et al., 2010), experience (Igbaria et al., 1991), promotability (Greenhaus et al., 1990), and negative affectivity (Moore, 2000). 


\subsection{Research Instruments}

The measurement scales were adapted from the well-established constructs in literature. Scale for technology led career growth was sourced from the work of Weng \& Hu (2009) where they have established a relationship between the perceived career growth and turnover intention. We have adapted the valid scale developed by Kopelman, et al., (1983) for measuring Technology led work-life balance dimension. The career satisfaction scale was adapted from Greenhaus et al. (1990). The scale has been widely used in the literature involving IT professionals (Jiang et al., 2012). All the responses were recorded on a five-point scale.

We performed pre-tests to ensure (a) construed meaning is same for different individuals; (b) the construed meaning is similar as intended. The face validity process was conducted with fellow academicians along with the small subset of the intended population. A pilot test was conducted with 65 IT professionals to conduct validity and reliability test on scale items. All the constructs displayed reliabilities above the acceptable limit of alpha greater than 0.70 . We examined both convergent and discriminant validity. The average variance extracted (AVE) score of at least 0.50 demonstrates that a set of items can represent a single underlying construct, thus indicating construct validity (Fornell \& Larcker, 1981). To ensure discriminant validity, square root of the AVE score need to be more than the correlations between the constructs. The AVE scores of our constructs ranged from 0.68 to 0.81 (see Table 1), and the square root of the AVE scores were more than the correlations (Fornell \& Larcker, 1981). Thus, all the variables indicated discriminant validity. We mean centred the variables to control for multicollinearity, which is common while using commensurate measures. We also confirmed the absence of influential outliers and problematic deviations. 


\begin{tabular}{|c|c|c|c|c|c|c|c|c|c|c|c|c|c|c|c|}
\hline S1. No. & Variables & Mean & SD & Alpha ${ }^{a}$ & 1 & 2 & 3 & 4 & 5 & 6 & 7 & 8 & 9 & 10 & 11 \\
\hline 1. & Age & 1.70 & 4.10 & -- & -- & & & & & & & & & & \\
\hline 2. & Gender & 1.70 & 0.50 & -- & 0.01 & -- & & & & & & & & & \\
\hline 3. & Marital status & 1.20 & 0.50 & -- & $0.57^{* *}$ & $-0.12^{*}$ & -- & & & & & & & & \\
\hline 4. & Previous experience & 2.60 & 0.89 & -- & $0.52^{* *}$ & 0.05 & $0.43^{* *}$ & -- & & & & & & & \\
\hline 5. & Promotability & 2.70 & 0.90 & -- & 0.09 & $0.12^{*}$ & 0.06 & $0.14^{*}$ & -- & & & & & & \\
\hline 6. & Negative affectivity & 4.01 & 1.60 & -- & $-0.23^{*}$ & 0.09 & $-0.16^{*}$ & $-0.14^{*}$ & $-0.19^{*}$ & -- & & & & & \\
\hline 7. & TLCG (Person) & 6.25 & 0.96 & 0.94 & -0.03 & -0.08 & 0.01 & 0.01 & 0.05 & 0.00 & 0.68 & & & & \\
\hline 8. & TLCG (Technology) & 5.15 & 1.36 & 0.94 & 0.05 & 0.03 & 0.02 & $0.10^{*}$ & $0.35^{*}$ & $-0.18^{*}$ & $0.31^{* *}$ & 0.72 & & & \\
\hline 9. & TWLB (Person) & 5.91 & 1.21 & 0.91 & -0.02 & $-0.15^{*}$ & -0.02 & 0.04 & -0.04 & -0.05 & $0.36^{* *}$ & 0.09 & 0.80 & & \\
\hline 10. & TWLB (Technology) & 4.37 & 1.70 & 0.93 & 0.02 & $0.13^{*}$ & 0.01 & 0.07 & -0.01 & $0.31^{* *}$ & 0.08 & $0.10^{*}$ & 0.09 & 0.81 & \\
\hline 11. & Career satisfaction & 4.07 & 1.49 & 0.90 & $0.12^{*}$ & 0.09 & 0.08 & $0.13^{*}$ & $0.63^{*}$ & $-0.24^{*}$ & 0.02 & $0.50^{* *}$ & -0.02 & 0.06 & 0.81 \\
\hline
\end{tabular}

Note: TLCG: Technology led career growth; TWLB: Technology led work-life balance; SD: Standard deviation; aAlpha: Cronbach alpha score

$\mathrm{N}=286 ;{ }^{*} \mathrm{p}<0.05 ;{ }^{* *} \mathrm{p}<.01$; The values at the diagonal represent AVE scores for the respective variables.

Table 1: Mean, standard deviation and correlation of all constructs. 


\section{Results}

\subsection{Analytical Representation of the Hypotheses}

The general equation to relate career satisfaction and the fit is represented by the algebraic expression (1)

$C S=b_{0}+b_{1} P+b_{2} T+b_{3} P^{2}+b_{4} P \times T+b_{5} T^{2}+e$

Where,

$b_{0}, b_{1}, b_{2}, b_{3}, b_{4}$, and $b_{5}$ represent the regression coefficient

$\mathrm{P}$ - IT professionals' individual expectation

$\mathrm{T}$ - IT professionals' experienced values

$\mathrm{P}^{2}-$ Squared term for individual expectation

PT - Interaction term for both expectation and experienced values

$\mathrm{T}^{2}-$ Squared term for experienced values

CS - Career satisfaction

\subsection{Testing hypotheses}

Hypothesis 1 proposed that the fit between the expected and the experienced career growth while working in a technology is positively related to career satisfaction. We conducted regression analyses for the fit in career growth aspects of technology with career satisfaction. We entered the terms $\left(\mathrm{P}, \mathrm{T}, \mathrm{P} X \mathrm{~T}, \mathrm{P}^{2}, \mathrm{~T}^{2}\right)$ in the regression analysis after controlling the effect of demographic and other important variables. The results indicated adjusted $\mathrm{R}$ square value of 0.27 . In Hypothesis 2, we proposed that the fit between the expected and the experienced work-life balance while working in a technology is positively related to career satisfaction. To test the hypothesis, we followed the above method and found the adjusted $\mathrm{R}$ square value to be 0.13 (see Table 2).

\begin{tabular}{lcc}
\hline Fit on Career satisfaction & Career growth & Work-life balance \\
\hline Constant & $3.76^{* *}$ & $3.91^{* *}$ \\
Age & 0.00 & 0.00 \\
Gender & $0.10^{*}$ & $0.06^{*}$ \\
Marital status & 0.36 & $0.30^{*}$ \\
Previous experience & 0.10 & 0.10 \\
Promotability & $0.17^{*}$ & 0.19 \\
Negative affectivity & $-0.22^{* *}$ & $-0.40^{* *}$ \\
\hline P & $-0.24^{*}$ & $-0.28^{* *}$ \\
T & $0.43^{* *}$ & $0.17^{* *}$ \\
P2 & -0.03 & 0.09 \\
P X T & $-0.09^{* *}$ & $-0.04^{* *}$ \\
$\mathrm{~T}^{2}$ & $0.05^{*}$ & $-0.13^{* *}$ \\
\hline F statistics & $5.56^{*}$ & $6.35^{*}$ \\
Adjusted $\mathrm{R}^{2}$ & 0.27 & 0.13 \\
$\mathrm{R}^{2}$ & 0.29 & 0.16 \\
\hline Note N $284 ;$ p & & \\
\hline
\end{tabular}

Note: $\mathrm{N}=284 ;{ }^{*} \mathrm{p}<0.05 ;{ }^{* *} \mathrm{p}<0.01$; F statistics represents the score for the higher order terms; $\mathrm{b}_{0}, \mathrm{~b}_{1}, \mathrm{~b}_{2}, \mathrm{~b}_{3}, \mathrm{~b}_{4}$, and $\mathrm{b}_{5}$ represent the regression coefficient

Table 2: Results of Polynomial Regression Analysis 
According to Edward and Parry (1993), when the joint coefficient of the three higher order terms $\left(\mathrm{P}^{2}, \mathrm{PX} \mathrm{T}\right.$, and $\left.\mathrm{T}^{2}\right)$ is significant, there is a significant effect of fit on the outcome variables. We tested both the models (career growth and work-life balance) and found the F-statistic values to be significant, thus, supporting Hypotheses 1 and 2. The details are provided in Table 2. Edwards and Parry (1993) further illustrated the use of response surface methods to test hypotheses along with polynomial regression analysis. Using response surface method threedimensional graphs were generated which depicted the position of all constructs in a threedimension frame. The RSM suggests some additional tests (using specific co-ordinates) to test the hypotheses.

Figure 1 and Figure 2 illustrates the output of response surface analysis conducted on predictor and criterion variable. The 3-dimensional plots are generated by plotting the regression coefficient for each regression equation. For hypothesis testing, we focused on three key features of the graph.

1. Stationary point (The point at which slope of the surface is zero in all directions)

2. Principal Axes (They run perpendicular to each other and intersect at the stationary point)

3. Slope of the surface along various lines of interest (principal axes, lines where principal components are equal $\{Y=X\}$. Description of relevant tests for our study is discussed in the following text.

Test 1: One of the significant coordinates in three-dimensional graphs is the stationary point $\left(\mathrm{X}_{0}, \mathrm{Y}^{0}\right)$ where the slope of the surface is zero in all directions. The equation for the stationary points can be represented as,

$\mathrm{X}_{0}=\left(\mathrm{b}_{2} \mathrm{~b}_{4}\right)-\left(2 \mathrm{~b}_{1} \mathrm{~b}_{5}\right) /\left(4 \mathrm{~b}_{3} \mathrm{~b}_{5}\right)-\mathrm{b}_{4}{ }^{2}$

$\mathrm{Y}_{0}=\left(\mathrm{b}_{1} \mathrm{~b}_{4}\right)-\left(2 \mathrm{~b}_{2} \mathrm{~b}_{3}\right) /\left(4 \mathrm{~b}_{3} \mathrm{~b}_{5}\right)-\mathrm{b}_{4}{ }^{2}$

The variables $\left(b_{1}, b_{2} \ldots b_{5}\right)$ are used to generate equations for the first and second principal axis. These values are derived from the result of polynomial regression analysis and represent the regression coefficient for $\mathrm{P}, \mathrm{T}, \mathrm{P} \times \mathrm{T}, \mathrm{P}^{2}, \mathrm{~T}^{2}$. Equations can be written as,

$\mathrm{Y}=\mathrm{p}_{10}+\mathrm{p}_{11} \mathrm{X}_{0}$

Where, $\mathrm{p}_{11}=\left(\mathrm{b}_{5}-\mathrm{b}_{3}+\operatorname{sqrt}\left(\left(\mathrm{b}_{3}-\mathrm{b}_{5}\right)^{2}+\mathrm{b}_{4}^{2}\right)\right) / \mathrm{b}_{4}$ and $\mathrm{p}_{10}=\mathrm{Y}_{0}-\mathrm{p}_{11} \mathrm{X}_{0}$

As adapted from Khuri and Cornell (1987)

$\mathrm{Y}=\mathrm{p}_{20}+\mathrm{p}_{21} \mathrm{X}_{0}$

Where, $\mathrm{p}_{21}=\left(\mathrm{b}_{5}-\mathrm{b}_{3}-\operatorname{sqrt}\left(\left(\mathrm{b}_{3}-\mathrm{b}_{5}\right)^{2}+\mathrm{b}_{4}{ }^{2}\right)\right) / \mathrm{b}_{4}$ and $\mathrm{p}_{20}=\mathrm{Y}_{0}-\mathrm{p}_{21} \mathrm{X}_{0}$

We analysed slope of three-dimensional graphs at various coordinate to test our hypotheses. Hypotheses 1 and 2 proposed that fit impacts career satisfaction. This implies that slope of the graph will be positive when there is a congruence between individual expectations and experiences from a given technology. Table 3 displays results of hypothesis testing using the response surface model. Hypotheses 1 and Hypothesis 2 will be supported if the value of $\mathrm{p}_{21}$, which represents the slope of the response surface, is significant (refer equation 3 ) and the value of $\mathrm{p}_{21}$ is not significantly different from 1 (Test 1 ). In addition, the value of $\mathrm{p}_{11}$ (refer equation 2); which represents the slope of the response surface curve, is not significantly 
different from 1 (Test 2). The results in Table 3 provided additional support to Hypothesis 1 and Hypothesis 2.

\begin{tabular}{ccccccc} 
Hypotheses & $\begin{array}{c}\text { Stationary point } \\
\mathbf{X}_{\mathbf{0}}\end{array}$ & $\mathbf{Y}_{\mathbf{0}}$ & $\mathbf{P}_{\mathbf{2 1}}$ & $\mathbf{P}_{11}$ & $\begin{array}{c}\text { Test results } \\
\mathbf{( p )}\end{array}$ & $\begin{array}{c}\text { Hypothesis } \\
\text { supported }\end{array}$ \\
\hline Hypotheses 1 & 2.50 & 9.50 & 0.72 & 1.12 & $\begin{array}{l}0.09^{*}(\text { Test } 1) \\
0.11^{*}(\text { Test 2) }\end{array}$ & Yes \\
\hline Hypotheses 2 & -0.25 & -1.30 & 0.79 & 1.05 & $\begin{array}{l}0.01^{* *} \text { (Test 1) } \\
\text { (Test 2) }\end{array}$ & Yes \\
\hline
\end{tabular}

\begin{tabular}{ccc}
\hline & \multicolumn{2}{c}{ Response surface feature $(\mathbf{X}=-\mathbf{Y}$, Misfit line $)$} \\
\cline { 2 - 3 } Hypotheses & Slope $\left(\mathbf{b}_{1}-\mathbf{b}_{2}\right)$ & Curvature $\left(\mathbf{b}_{3}-\mathbf{b}_{4}+\mathbf{b}_{5}\right)$ \\
\hline Hypotheses 3(a) & $-0.19^{*}$ & $-0.18^{*}$ \\
Hypothesis 3(b) & $-0.45^{*}$ & $0.18^{*}$ \\
\hline
\end{tabular}

Note: ${ }^{*} \mathrm{p}<0.05 ;{ }^{* *} \mathrm{p}<0.01$

Table 3: Results of Response surface analysis examining career satisfaction

To test our Hypothesis $3(a, b)$, we were particularly interested in effects on career satisfaction when IT professionals exhibit a higher degree of expectations than the experienced aspects of technology. Thus, Hypothesis 3 particularly involve the movement along the misfit or incongruence line $(X=-Y)$. We examined both slope and curvature of the graph along the incongruence line and found both to be significant. This implies that as we move along the misfit line higher the expectations regarding (a) TCG and (b) TWLB as compared to the experienced TCG and TWLB, lesser will be the career satisfaction. Hypotheses $3(a, b)$ will be supported if slope $\left(b_{1}-b_{2}\right)$ and the curvature $\left(b_{3}-b_{4}+b_{5}\right)$ are significant (see Table 3$)$ for both TCG and TWLB. We found support for both the hypotheses (Table 3 and Figure $1 \& 2$ ).

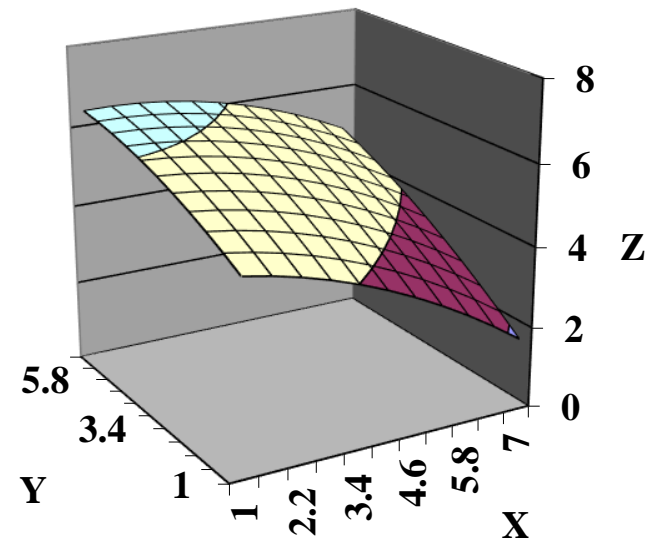

Figure 1: Response surface graph predicting career satisfaction against TCG

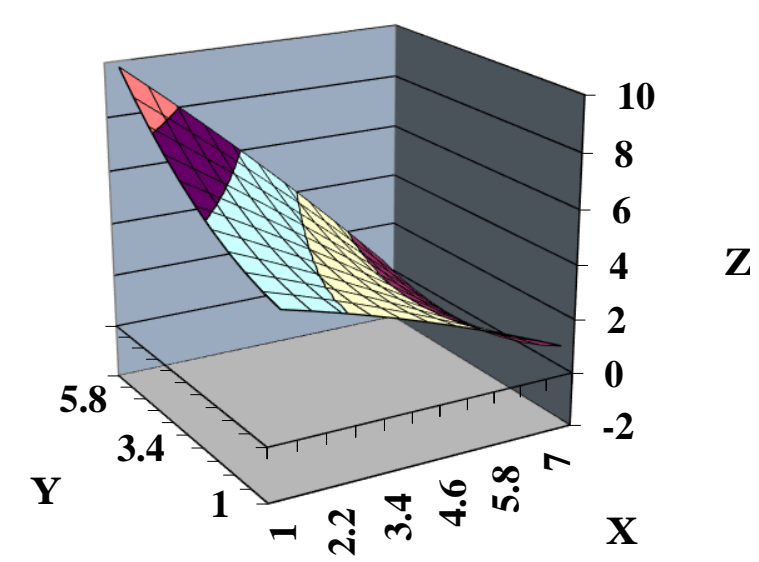

Figure 2: Response surface graph predicting career satisfaction against TWLB 


\section{Discussion}

Our findings highlighted the need to investigate relevant 'environmental' aspects to understand work outcomes of IT professionals. In the present study, we examined 'technology' as a critical 'environmental' factor to explain career satisfaction of IT professionals. The IS literature is rich in studies exploring different aspects of technology. While most of the studies focus on usage and adoption of technology, studies exploring the interpretation of technology from the career perspective of IT professionals are at best limited. In the present study, we have explored two distinct technology-related aspects, i.e., technology led career growth and technology led work-life balance. Summarizing the findings of the study, we propose that career satisfaction of an IT professional is driven by the fit between his/her expectations and experiences while working in a technology. Our findings indicate that individuals who perceive that they are working in a favourable technology are more prone to experience greater career satisfaction. In addition, the support for our divergence hypotheses (Hypotheses $3 \mathrm{a}$ and $3 \mathrm{~b}$ ) indicated that the misfit between expectation and experience while working in a technology lead to reduced career satisfaction. Our study further highlighted that it is not only about the misfit but the nature of the misfit that affected career satisfaction of IT professionals. For instance, our results indicated that when expectation (on both career growth and work-life balance) is more than the experienced outcomes, compared to the other way (when experienced outcomes are more than the expectations) the impact on career satisfaction is high.

\subsection{Implications for theory}

There is a substantial body of knowledge in the IS literature that has demonstrated that technology is critical towards the growth and profitability of organizations (Mithas \& Rust, 2016; Sabherwal \& Jeyaraj, 2015). In addition, technology has been accepted as an enabler of the digital transformation of business markets (Hess et al., 2016; Majchrzak et al., 2016). Our study contributes to this body of knowledge in a meaningful way by exploring aspects of technology as important predictors of career satisfaction among the IT professionals.

Our study builds and extends the existing theory in the individual-technology interface. Recognizing the contribution of prior studies such as affordance theory (Leonardi, 2011; Markus \& Silver, 2008), expectation disconfirmation theory (EDT) and P-O fit/P-J fit theory (Venkatesh \& Goyal, 2010; Venkatesh et al., 2017) the present study proposed a set of unique technology led aspects which are relevant for the IT professionals, especially their career satisfaction.

Our findings extend the P-E fit literature by reconceptualizing technology as the "environment" component of the framework to explain career satisfaction of IT professionals. Considering centrality of technology in the career of IT professionals, we chose two important aspects, namely career growth and work-life balance aspects of technology in the present study. The findings of our study depicted that the match between their expectations (related to career growth and work-life balance) from the technology the IT professionals are working in and their experiences with those aspects of technology explained significant variance in their career satisfaction. Our study contributes to this stream of literature by (1) extending the P-E fit framework in a unique context and (2) examining that individual expectation related to technology plays a major role in determining significant work-related outcomes such as career satisfaction. 


\subsection{Implications for practitioners}

The study has significant implications for practitioners, as supervisors are facing serious challenges in managing IT professionals. With increasing instances of shorter employment relationships, the management of careers has become more self-directed (Sullivan \& Baruch, 2009) more so for the IT professionals (Joseph et al., 2012). Career satisfaction is important as it influences significant outcomes such as productivity, commitment and job satisfaction (MacCrory et al., 2016). There is a need for the organizations to "develop more sophisticated strategies to acquire and retain top talents for organizational success" (Huang \& Zhang, 2016, p. 803). Given that IT professionals experience higher levels of stress (Moore, 2000) and stress related outcomes, our finding provides a novel approach to look at these issues. Our study demonstrated that the 'technology', the IT professionals work in, is central to their work outcomes. Technology being a significant aspect of their work life, the match/ mismatch between expectations from the technology and experience while working in that technology play an important role in explaining career related outcomes such as career satisfaction. Scholars agree that "IT professionals derive motivation from what they do" (Ahmed et al., 2017 , p. 04). Hence, organizations need to explore ways to factor in the expectations of professionals while allocating technology to them. Our study demonstrated that by devising mechanisms which incorporate IT professionals' technology-related expectations, in project/ technology allocation may be effective in enhancing career satisfaction of these professionals.

\subsection{Limitations and future research}

We believe that adopting subjective measures in the study to capture person-environment dimensions have generated findings which are based on individual perceptions and beliefs. Objective measures tend to report P-E fit which is believed to be free from human bias. The objectivity can be maintained by employing multi-source data reporting. However, by synthesizing literature from both cognitive and behavioural perspectives, we noticed that subjective measures may be more relevant and pertinent than objective measures (Edwards et al., 2006; Venkatesh et al., 2017). Further, subjective measures are more proximal indicators of individual perception and attitudes than are the objective measures (Edwards et al., 2006). For these reasons, we found subjective measures to be more appropriate for the present study. In the present study, we have limited the work outcome to career satisfaction. Future studies may explore the expectation-experience match/mismatch from the technology one is working in to explain other important work outcomes such as stress and turnover. In addition, our study is limited to Indian cultural context; similar studies may be conducted in different cultural settings to understand the cultural variance of the expectation-experience (mis-)match in predicting work outcomes.

\section{Conclusion}

Technology is core to the IT professionals' work-life. Hence, it is important to understand, the expectations of these professionals from the technology they are working in. Surprisingly the research in this domain is scarce. The present study explained two important expectations from the technology (namely career growth and work-life balance) and demonstrated their impact on career satisfaction. Based on a rigorous study and using a novel methodology, the study highlighted the need to refocus the attention on expectations and experiences of IT professionals' while working in a technology to explain their work outcomes. 


\section{References}

Ahmed, S., Taskin, N., Pauleen, D. J., \& Parker, J. (2017). Motivating information technology professionals: The case of New Zealand. Australasian Journal of Information Systems, 21, 130.

Armstrong, D. J., Brooks, N. G., \& Riemenschneider, C. K. (2015). Exhaustion from information system career experience: Implications for turn-away intention. MIS Quarterly, 39(3), 713-727.

Atapattu, M., \& Sedera, D. (2014). Agility in consumer retail: Sense-response alignment through the eyes of customers. Australasian Journal of Information Systems, 18(2), 111-132.

Ayyagari, R., Grover, V., \& Purvis, R. L. (2011). Technostress: Technological antecedents and implications. MIS Quarterly, 35(4), 831-858.

Brown, S. A., Venkatesh, V., \& Goyal, S. (2012). Expectation confirmation in technology use. Information Systems Research, 23(2), 474-487.

Chen, Z., Powell, G. N., \& Greenhaus, J. H. (2009). Work-to-family conflict, positive spillover, and boundary management: A person-environment fit approach. Journal of Vocational Behavior, 74(1), 82-93.

Chilton, M. A., Hardgrave, B. C., \& Armstrong, D. J. (2005). Person-job cognitive style fit for software developers: The effect on strain and performance. Journal of Management Information Systems, 22(2), 193-226.

Dawis, R. V., \& Lofquist, L. H. (1984). Psychological theory of work adjustment: An individualdifferences model and its applications. Minneapolis: University of Minnesota Press.

Edwards, J. R., Cable, D. M., Williamson, I. O., Lambert, L. S., \& Shipp, A. J. (2006). The phenomenology of fit: Linking the person and environment to the subjective experience of person-environment fit. Journal of Applied Psychology, 91(4), 802-827.

Edwards, J. R., \& Parry, M. E. (1993). On the use of polynomial regression equations as an alternative to difference scores in organizational research. Academy of Management Journal, 36(6), 1577-1613.

Fornell, C., \& Larcker, D. F. (1981). Evaluating structural equation models with unobservable variables and measurement error. Journal of Marketing Research, 18(1), 39-50.

Fu, J-R., \& Chen, J. H. F. (2015). Career commitment of information technology professionals: The investment model perspective. Information \& Management, 52, 537-549.

Furnham, A., \& Schaeffer, R. (2011). Person-environment fit, job satisfaction and mental health. Journal of Occupational and organizational Psychology, 57(4), 295-307.

Ginzberg, M. J., \& Baroudi J. J. (1988). MIS careers: A theoretical perspective. Communications of the ACM, 31(5), 586-594.

Greenblatt, E. (2002). Work/life balance: Wisdom or whining. Organizational Dynamics, 31(2), 177-193.

Greenhaus, J. H., Parasuraman, S., \& Wormley, W. M. (1990). Effects of race on organizational experiences, job performance evaluations, and career outcomes. Academy of Management Journal, 33(1), 64-86. 
Gupta, Y. P., Guimaraes, T., \& Raghunathan, T. S. (1992). Attitude and intentions of information center personnel. Information and Management, 22(3), 151-160.

Han, G. (2010). Trust and career satisfaction: The role of LMX. Career Development International, 15(5), 437-458.

Hess, T., Matt, C., Benlian, A., \& Wiesböck, F. (2016). Options for formulating a digital transformation strategy. MIS Quarterly Executive, 15(2), 123-139.

Hill, E. J., Hawkins, A. J., Ferris, M., \& Weitzman, M. (2001). Finding an extra day a week: The positive influence of perceived job flexibility on work and family life balance. Family Relations: Interdisciplinary Journal of Applied Family Science, 50(1), 49-58.

Hsu, M. K., Jiang, J. J., Klein, G., \& Tang, Z. (2003). Perceived career incentives and intent to leave. Information and Management, 40(5), 361-369.

Huang, P., \& Zhang, Z. (2016). Participation in open knowledge communities and jobhopping: Evidence from enterprise software. MIS Quarterly, 40(3), 785-806.

Igbaria, M., Greenhaus, J. H., \& Parasuraman, S. (1991). Career orientations of MIS employees: An empirical analysis. MIS Quarterly, 15(2), 151-169.

Jans, N. A. (1989). Organizational commitment, career factors and career/life stage. Journal of Organizational Behavior, 10, 247-266.

Jawahar, I. M., \& Liu, Y. (2016). Proactive personality and citizenship performance: The mediating role of career satisfaction and the moderating role of political skill. Career Development International, 21(4), 378-401.

Jiang J., \& Klein, G. (1999). Supervisor support and career anchor impact on the career satisfaction of the entry-level information systems professional. Journal of Management Information Systems, 16(3), 219-240.

Jiang, J. J., Klein, G., \& Saunders, C. (2012). Discrepancy theory models of satisfaction in IS research. In Y. L. Dwivedi, M. R. Wade, \& S. L. Schneberger (Eds.), Information systems theory: Explaining and predicting our digital society (pp. 355-381). New York: Springer publishing.

Joseph, D., Boh, W. F., Ang, S., \& Slaughter, S. A. (2012). The career paths less (or more) travelled: A sequence analysis of it career histories, mobility patterns, and career success. MIS Quarterly, 36(2), 427-452.

Khuri, A. L. \& Cornell, J. A. (1987). Response surfaces: Designs and analyses. New York: Marcel Dekker Inc.

Kopelman, R. E., Greenhaus, J. H., \& Connolly, T. F. (1983). A model of work, family, and interrole conflict: A construct validation study. Organizational Behavior and Human Performance, 32(2), 198-215.

Kristof-Brown, A. L., Zimmerman, R. D., \& Johnson, E. C. (2005). Consequences of individuals' fit at work: A meta-analysis of person-job, person-organization, person-group and person-supervisor fit. Personnel Psychology, 58(2), 281-342.

Lee, P. C. B. (2011). Computer professionals and their perceived workload. Australasian Journal of Information Systems, 17(1), 5-22. 
Leonardi, P. M. (2011). When flexible routines meet flexible technologies: Affordance, constraint, and the imbrication of human and material agencies. MIS Quarterly, 35(1), 147-167.

Locke, E.A. (1976). The nature and causes of job satisfaction. In M. D. Dunnette (Ed.), Handbook of industrial and organizational psychology (pp.1297-1349). Chicago: Rand McNally College Publishing.

Lounsbury, J. W., Moffitt, L., Gibson, L. W., Drost, A. W., \& Stevens, M. (2007). An investigation of personality traits in relation to job and career satisfaction of information technology professionals. Journal of Information Technology, 22, 174-183.

Lounsbury, J. W., Park, S. H., Sundstrom, E., Williamson, J., \& Pemberton, A. (2004). Personality, career satisfaction, and life satisfaction: Test of a directional model. Journal of Career Assessment, 12, 395-406.

MacCrory, F., Choudhary, V., \& Pinsonneault, A. (2016). Designing promotion ladders to mitigate turnover of IT professionals. Information Systems Research, 27(3), 648-660.

Majchrzak, A., Markus, M. L., \& Wareham, J. (2016). Designing for digital transformation: Lessons for information systems research from the study of ICT and societal challenges. MIS Quarterly, 40(2), 267-277.

Mithas, S., \& Rust, R. T. (2016). How information technology strategy and investments influence firm performance: Conjectures and empirical evidence. MIS Quarterly, 40(1), 223-245.

Moore, J. E. (2000). One road to turnover: An examination of work exhaustion in technology professionals. MIS Quarterly, 24(1), 141-168.

Moreno, A. M., Sanchez-Segura, M. I., Medina-Dominguez, F., \& Carvajal, L. (2012). Balancing software engineering education and industrial needs. Journal of Systems and Software, 85(7), 1607-1620.

Ng, T.W.H., Eby, L.T., Sorensen, K. L., \& Feldman, D. C. (2005). Predictors of objective and subjective career success: A meta-analysis. Personnel Psychology, 58(2), 367-408.

Ngo, H-Y., \& Hui, L. (2018). Individual orientations and career satisfaction: The mediating roles of work engagement and self-efficacy. Journal of Career Development, 45(5), 425-439.

Porter, L.W., \& Steers, R.M. (1973). Organizational, work, and personal factors in employee turnover and absenteeism. Psychological Bulletin, 80(2), 151-176.Rambur, B., McIntosh, B., Palumbo, M.V., \& Reinier, K. (2005). Education as a determinant of career retention and job satisfaction among registered nurses. Journal of Nursing Scholarship, 37, 185-192.

Rehfuss, M.C., Gambrell, C.E., \& Meyer, D. (2012). Counselors' perceived person-environment fit and career satisfaction. Career Development Quarterly, 60(2), 145-151.

Sabherwal, R., \& Jeyaraj, A. (2015). Information technology impacts on firm performance: An extension of Kohli and Devaraj (2003). MIS Quarterly, 39(4), 809-836.

Sarker, S., Sarker, S., \& Jana, D. (2010). The impact of the nature of globally distributed work arrangement on work-life conflict and valence: The Indian GSD professionals' perspective. European Journal of Information Systems, 19(2), 209-222. 
Shockley, K.M., \& Allen, T.D. (2018). It's not what I expected: The association between dualearner couples' met expectations for the division of paid and family labor and wellbeing. Journal of Vocational Behavior, 104, 240-260.

Speier, C., \& Venkatesh, V. (2002). The hidden minefields in the adoption of sales force automation technologies. Journal of Marketing, 66(3), 98-111.

Sullivan, S. E., \& Baruch, Y. (2009). Advances in career theory and research: A critical review and agenda for future exploration. Journal of Management, 35(6), 1542-1571.

Tarafdar M., Tu, Q., Ragu-Nathan, B. S., \& Ragu-Nathan T. S. (2007). The impact of technostress on role stress and productivity. Journal of Management Information Systems, 24(1), 301-328.

Venkatesh, V., \& Goyal, S. (2010). Expectation disconfirmation and technology adoption: Polynomial modeling and response surface analysis. MIS Quarterly, 34(2), 281-303.

Venkatesh, V., Windeler, J.B., Bartol, K.M., \& Williamson, I.O. (2017). Person-organization and person-job fit perceptions of new IT employees: Work outcomes and gender differences. Management Information Systems Quarterly, 41(2), 525-558.

Weng, Q. X., \& Hu, B. (2009). The structure of career growth and its impact on employees' turnover intention. Industrial Engineering and Management, 14(1), 14-21.

Weng, Q. X., McElroy, J. C., Morrow, P. C., \& Liu, R. (2010). The relationship between career growth and organizational commitment. Journal of Vocational Behavior, 77(3), 391-400.

Copyright: (C 2019 Tomer \& Mishra. This is an open-access article distributed under the terms of the Creative Commons Attribution-NonCommercial 3.0 Australia License, which permits non-commercial use, distribution, and reproduction in any medium, provided the original author and AJIS are credited.

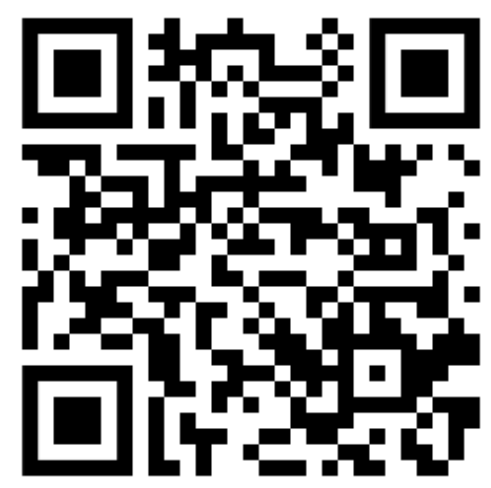

